\title{
Planning for Development of Favorable District for the Elderlies; Case Study: Kerman Arg District
}

\author{
Hashem Vazirizadeh $^{1} \&$ Ismaeil Shieh $^{2}$ \\ ${ }^{1}$ Student of Urban Planning, Islamic Azad University, Qazvin Branch, Department of Urban Planning, Qazvin, \\ Iran \\ ${ }^{2}$ Professor of Urban Planning Univesity of Science and Technology Iran, Iran \\ Correpondence: Ismaeil shieh, Professor of Urban Planning Univesity of Science and Technology Iran, Iran. \\ E-mail: es_shieh@iust.ac.ir
}

Received: December 22, 2016

Accepted: January 17, 2017

Online Published: March 30, 2017

doi:10.5539/jsd.v10n2p170

URL: https://doi.org/10.5539/jsd.v10n2p170

\begin{abstract}
By increase of age group of people older than 60 years and problems of aging period, it seems necessary to provide favorable environmental conditions in order to increase life expectancy of this group. One of the public spaces which had been much underlined in traditional urban development and has double importance for the elderly and receives less attention today is the district. This paper, aiming at planning urban districts tailored to the needs of the elderly, provides required criteria in district planning through descriptive-analytical method. Finally, by offering components of: familiarity, readability, dignity, accessibility, convenience, security and beautification in the district planning process of Kerman Arg district, these components are applied.
\end{abstract}

Keywords: elderly, planning, district, development, favorable

\section{Introduction}

\subsection{Research Questions}

Physical problems of the elderly period need to provide favorable environmental conditions for presence of this group. Lack of attention to this important point has made the problems more complex. Non-favorable environmental conditions for further presence of this generation in urban spaces have caused marginalization of this group. Reduce of mobility and staying only in closed spaces will cause more problems for this group. The elderly due to their accumulated experience and knowledge and receiving respect from other age groups, by their presence in urban spaces will have social and moderating role that this important point, because of lack of required facilities for the elderly throughout the districts and their decreasing presence has little by little been forgotten. Old age is a stage of life that encompasses all living creatures including human being. Aging cannot be stopped but by using suitable methods and cares, disorders and disabilities that elderly people face with them can be prevented or delayed so that they can enjoy a long life with health and welfare which has always been human desire. Life environment and habitat are among the most important constituent parts of surroundings environment of human beings. With increase of the number of elderly people in the world, international organizations called for particular attention of the world to this age group. Examining the limitations due to old age will have much impact on providing suitable environment for all people who will someday get close to the threshold of old age. Certainly such an environment will be favorable for all special groups of society, especially children and handicaps. The experiences in designing and improvement of urban spaces and its compliance with conditions of physical-motion handicaps in different countries show that using some simple arrangements, a great part of the society can be called to active participation. Thus, in this paper, we decided to examine the elderly group specifically, and by recognizing their needs try to plan the development of favorable district for them.

1) What policies and design principles must be followed for planning a desirable residential neighborhood for the elderly?

2) How is it possible to meet the needs of the elderly by good planning of a residential neighborhood? 


\subsection{Research Goals}

A. Understanding the characteristics and needs of the elderly:

Clarifying the needs associated with the generation that once took the reins of family affairs and the whole community is one of the main objectives of this study. As stated, this generation is the preserver of events and happenings that are inextricably linked with the spirit of the younger generation and understanding the needs of those who one day the younger generation will replace, either in terms of morality and spirituality or in terms of stability of human needs is very important. Urban areas should always be planned and designed in such a way that can be suitable for various social groups and there should not be an age limit regarding the possibility of entering into those environments, the easy access happens when analyzed with the needs of the target groups.

B. 2-Offering residential neighborhood planning principles in accordance with the requirements of the elderly:

Housing needs are considered among the basic human needs. Suitable dwelling is a place to relax with family members and it encompasses a need beyond the physical aspect. Extensive studies have shown that bad housing causes psychological problems, as well as other associated risks, having stated this it can be said that, this requirement for a generation who are physically weak because of aging and psychologically need more attention is more serious. This is also true in the case of residential neighborhoods. In addition, the neighborhoods have been supplier of the needs of different age groups, paying attention to designing and planning in regard to the needs of the elderly that has been less heeded can pave the way for more unity between the elderly and the younger age groups and finally, residential neighborhoods include environments bigger than family and smaller than the community.

C. 3-Offering an instance of desirable residential neighborhood plan for the elderly:

Plan tailored to the needs of the elderly for the attendance and presence of these groups and to promote their association with the younger age groups that leads to their mental freshness and improved physical health are the purposes of the intended research. It is worth noting that the presence of this group of people in urban environments results in a reduction of anomalies (as the elder) in the neighborhoods. On the other hand, this group will continue to live with more mental vitality. Preparation and foundation (paving the way) for more and easier presence of this group in the residential areas is the purpose of the intended research.

\section{Method}

this research is descriptive-analytical and is based on librarial explorations and field studies and have been conducted by submitting questionnaires to the related organizations for having access to the required information (citizens' views).

\subsection{Theoretical Foundations}

District is the main pillar of the urban fabric and balance of social life in cities depend very much on maintaining district unit. It is by presence of districts that living in the biggest cities can be pleasant and human. During the twentieth century, using the idea of residential district has become the centerpiece of many new theories of urban development, and in order to deal with various urban problems such as management issues, social and human relationships, health and welfare issues, and also meaning and identity dimensions, this idea has been embraced (Gharavi Al-khansari, 2006: 23) . It is clear that in every city there are diverse and different districts in terms of different physical, social, welfare and ... aspects. Iranian cities are also no exception of this rule and from ancient times they had been divided to different districts based on the feature of their residents. This could be a religious factor such as Armenians or Jews districts in Isfahan, or a racial factor like the Turks and Arabs districts in Tehran, or several other factors including the type of occupation of the people in a district, living and economic conditions of people and so on. Still in many cities such classifications can be observed.

In terms of physical and biological age:

Physical age and aging has direct impact on people's daily functions and activities. So physical aging in fact occurs when a person has physical problems for doing his/her activities. According to the World Health Organization definition in January 1981, the elderly are among the disabled. This organization has defined disability as disorder in the relationship between the person and environment and has introduced the elderly among the physical disabled people (Teymoori,2009: 92).

\subsection{In Terms of Social Age}

Social age is in fact the amount of presence and roles that a person has in the community that however is not consistent with time age. Generally, people are retired while they still have required power and they want to 
work. Often, social old age occurs much earlier than old age based on time and this is along with physical problems and consequences. Given that aging is a phenomenon that is along with biological, psychological and social particular aspects, it seems that definition of aging based on calendar age is not inclusive about all the elderly and an old person must be old both in terms of his/her birth certificate and in physical, psychological and social terms (Kakayee, 2007: 36) .

Cognitive problems of the elderly in the environment are discussed in relation to three general topics:

Environment familiarity; keeping concentration in the environment; routing

These problems often cause the most common type of negative emotions in the urban environment, including feeling of fear, apprehension, especially in people with dementia in formal settings, confusion, embarrassment, especially when they are lost, and loneliness (Barton, 2006: 56) [9].

Environment familiarity: in this research, familiarity points to the amount of recognizing urban environment for the elderly and the ease of their understanding of the environment. Most of the elderly are afraid of presence in unfamiliar places meaning the places that their perception is difficult for them. Many environments are designed in accordance with detailed patterns and the elderly tend that their normal expectations from special spaces and their contents will be met. For example, when entering a business street, they usually expect to see rows of various shops and restaurants. If these expectations are not met, the space may be very confusing; just as the guide to internal designing of nursing homes for the elderly also emphasize (Barton, 2006: 62) .

Keeping concentration in the environment: one of the other problems of the elderly is inability to maintain concentration and focus in the environment and this causes them to lose their position and not know where they are and what they do. This problem is created by various factors; even sometimes hearing a sudden noise such as honking cars or collision with an obstacle or jogging of people will cause loss of concentration. However, function and performance is important for the elderly, especially the ones with dementia. These people do not remember names, but recognize performances and functions. For example, they know that there is a hospital in that street, but they cannot remember its name. These people even do not remember that the place is called hospital, but they know that it is a place where patients are treated. So, places and streets that have mixing functions with architectural designs and buildings that are various in local style, size, shape, materials and colors, not only make the district more attractive, but also help maintaining of focus in people with dementia. Most of the elderly prefer streets with a gentle twist to direct long streets. The reason has been explained as this: "turns and twists have more attractiveness" and "there is more variety" and "it creates different scenes". Also it helps keeping concentration in order for preventing confusion and bewilderment. Relatively thin streets also, because of more closeness of signs in vicinity of individuals and the feeling of convenience and being cozy and a lower risk compared to wide streets, help people to maintain concentration (Barton, 2006: 62).

Routing: one of the other problems of the elderly is routing and determining direction. Few elderlies who have routing problems use maps or noted directions in order to find their way in the district. By increase of age, using a map and following it will become more difficult for many elderlies (Barton, 2006: 62).

\subsection{Sustainable District}

Sustainable development approach is rooted in dissatisfaction with the results of socio-economic growth and development in cities in terms of ecology (Sarrafi, 2000: 8). One of the concerns of urban planning is the concept of sustainability. Sustainability is defined by the World Commission on Environment and Development as this: sustainable development is the kind of development that provides the needs of present generation without compromising the future generation to meet their needs and aspirations (Larrain, 2002: 43) . Sustainable development decision makings should involve all levels of activities and places (Eftekhari, 2004: 108).Sustainability requires that decision makings and activities will lead to investment in local social capacities so that by this way, in addition to strengthening it, at the special conditions at least the natural, social, human or economic capitals will not be decreased (Eftekhari, 2004: 93).

Sustainable and favorable district for the elderly:

By increase of age, dependence of the elderly on their home and neighborhoods and district increases and physical changes in these environments (especially if they are significant) will cause damage or loss of social spaces created in these physical spaces (Zabetian, 2009: 54).

Also the results of researches have shown that re-settlement and change of habitat has negative effects in the elderly. Therefore, physical changes in the elderly spaces should be very subtle and gradual and the spaces must be tailored to match the needs of the elderly (Zabetian, 2009: 54). 


\subsection{Indices of Tailoring Elderly-Friendly Urban Spaces}

Based on the results of the field studies (conducted in England) six main keys of designing have been obtained that are briefly referred to below:

1) Familiarity

In fact, the elderly and especially those with dementia suffer from short-term memory problems, so repeating of familiar sights in the city helps them in routing. Also any kind of change in the environment will cause their getting out of order and being confused and this issue about urban furniture with modern styles such as benches and bins, telephone kiosks and new bus stations also can be annoying for them.

2) Readability

In readable streets, understanding the pathways and trails network is easy. Very few studies on the issue of finding the way and the ability of finding direction in the elderly in the external environment have been done so far and there have been no studies on patients with dementia. People usually visualize a mental map from the route they want to walk in but the elderly also review the signs they are encountered with in the route, in their mind.

\section{3) Being recognizable}

The elderly communicate with simple and illustrative styles and for example, modern buildings which may not have clear and easy entrances and facades may be considered difficult for them and this may cause that they will mistakenly enter a more personal space or become reluctant to use public space. Or for example, a large number of the elderly with dementia have problems with use of revolving doors and moving frames because they are not opened on one joint.

4) Accessibility

At the macro level of urban planning, the elderly have many problems with functionalist urban development. Because in this attitude, activities are separated through zoning and subsequently it will be followed by physical and social scattering. In addition, in this type of planning, access to services and facilities is difficult and dependence on cars is doubled.

\section{5) Convenience}

Existence of spaces for sitting and refreshment and clean toilets at ground level, leveling the surfaces and use of gentle slopes and ramps instead of stairs, escalators in the pedestrian bridges or underpasses, Shelter spaces such as colonnades (hallways with two or one side open which keep the pedestrians from the atmospheric elements like rain, sun, etc.) and such cases can provide convenience of the elderly and widely all vulnerable classes as citizens.

\section{6) Security}

Space security refers to the feeling of enjoy from the environment without any fear. Poor vision disorders and Shaky walking causes the risk of falling of the elderly. Also some of them are afraid of being attacked especially at night or walking in solitude places and underpasses. Because the person does not know what awaits him/her and there is no monitoring on that space. The elderly preferred phone boxes to open kiosks, because they think someone may attack them from behind (Zabetian, 2009: 123).

\section{Results}

In [Table 1] this paper has been done following the previous researches that have studied the conditions of the elderly group, including: researches by Elham Zabetian, Mohammad Reza Pourjafar and ... [1 and 2], and tries to continue the procedures of these researches. The elderly are a group of citizens that have special features. The stated experiences show that the elderly have greater dependence on public transports and walking; and since slower pace, poorer vision and imbalances make their moving difficult, urban spaces should be designed such that consider their disabilities. In this article, using partnership approach and direct interview and interaction with the elderly, the best pathology in identifying indices required for the elderly, including: familiarity of the environment, readability, accessibility, being recognizable, convenience and security, are provided. Social urban welfare can be stated in welfare criteria in the structure of a city which provides the possibility of equal life in term of provision of urban services, facilities and amenities and provides flourishing life for all social classes, especially the elderly.

The method of analysis and assessment of the study area: 
Table 1. Population characteristics of Kerman, the ancient structure, and Arg district

\begin{tabular}{llll}
\hline Description & Kerman city & Ancient structure area & Arg district \\
\hline Population (2011) & 524132 & 28467 & 5340 \\
Male & 262431 & 15612 & 3132 \\
Female & 261701 & 14730 & 2208 \\
Family & 131033 & 7116 & 1335 \\
Family dimension & 4 & 4 & 4 \\
\hline
\end{tabular}

Source: Housing and Urban Development Organization of Kerman

\subsection{Investigating the Situation of Kerman Arg District}

In [Figure 1] arg district due to its special significance can be further analyzed and recognized. This square as the link between south and north (the ancient structure of the city located at Kerman center), and also Ganjalikhan market at its east and Taleghani avenue in its west, has high functional importance. Kerman Arg district is located within the ancient structure area of Kerman that due to its historical structure, the original native inhabitants of the area can be cited as the ability for the considered structure. Given the purpose of the present article about planning the district according to the needs of the elderly and its modeling for ancient and historical areas in order for better use and having leisure time for the elderly, this point can be mentioned that as the elderly are valuable human force, full of experience and past culture, providing the context for their increasing presence, especially in urban spaces with leisure function, can provide the required background and context as an approach for more and more respect to these classes, both for target groups (the elderly) and for the other social classes.

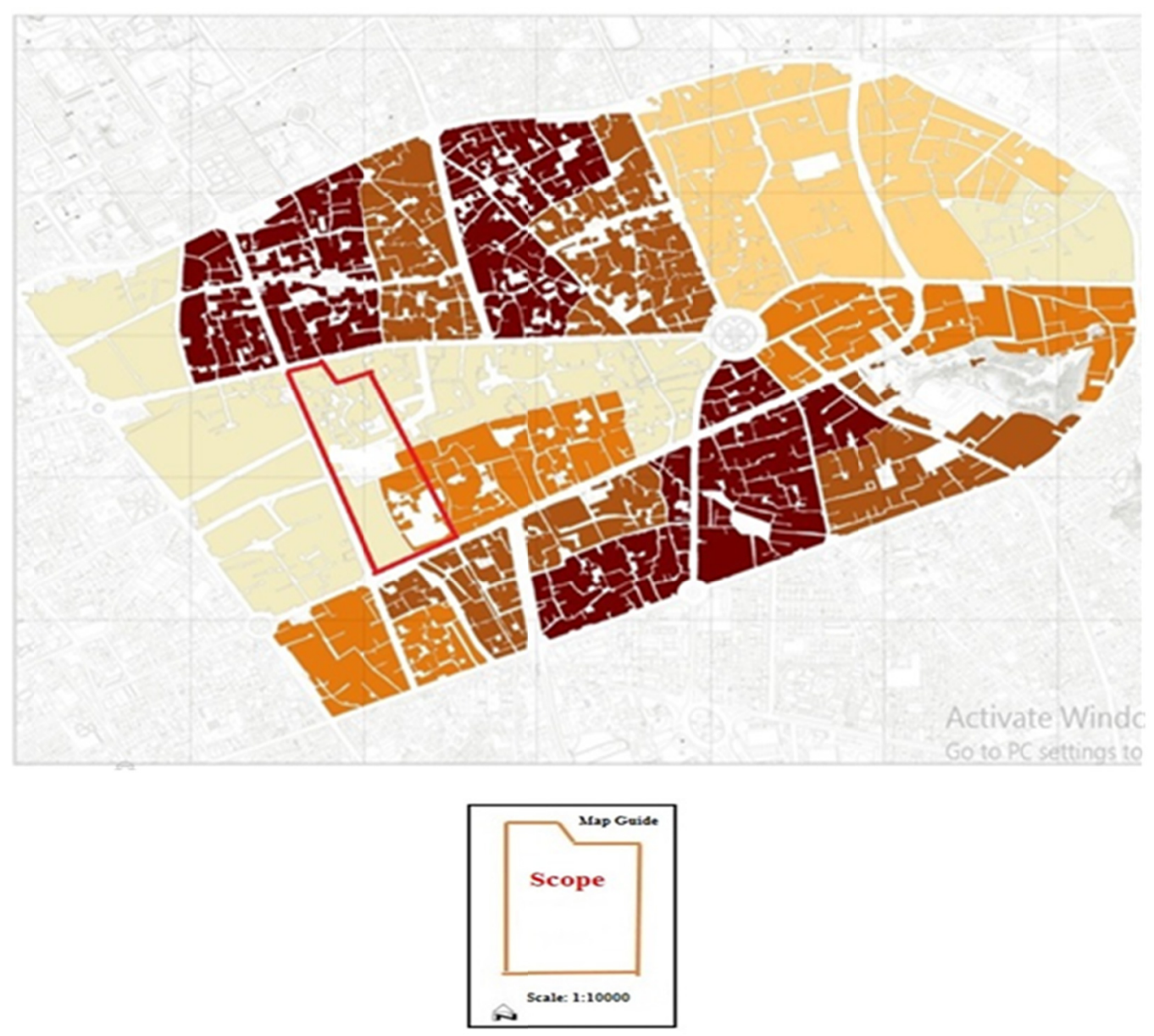

Figure 1. Scope of the ancient structure and Arg district

Source: Sharestan consultant engineers 
Given the characteristics of the ancient structure as the immediate scope of the area under research, some points can be mentioned in this regard. On one hand, regarding existence of historical and identity-related monuments in this context, it can be noted that Arg square itself is linked with these monuments and is considered the linking chain of Kerman caravanserai and Kerman market and this link in the body can also refer to coordination in the function. On the other hand, relative integration in the function of the ancient structure can also be mentioned that not only enjoys diversity and being organic, but also the area has a coherent whole and has benefited from it. It should be noted that some part of these features also have risen up from the natural properties of Kerman city in not too far years ago. As it turns, south side of Argeh district which is well-known as Godal e Khesht-mal Ha (Bricklayers' pit) is almost vacant land and planning for this district can have particular importance. This planning should be considered paying attention to the function of the complex. Among these, leisure complexes can be mentioned which are used in order to meet the needs of residents of the district and the immediate area (ancient structure). This need is particularly more necessary for people with disabilities, including the elderly. Because the elderly need suitable spaces for spending their life and their presence is subject to creation of such spaces. Given the existing functions in Kerman Arg district, it can be expressed that a high percentage of functions of this district is service and commercial functions and given the situation of the district in the ancient structure, it can be expected that commercial and service functions play the key role in the district in future. As is also mentioned in the proposed model, commercial, service and leisure functions play significant role in the district. This issue is examinable from several aspects. Firstly the residents of this structure that in case of any change in their habitat will be under the direct impact of gains and losses of the changes and the various aspects of these changes must be considered and planned desirably. Studies have shown that these changes, if it is realized without the consent of residents, will have harmful social effects on them. Research also has shown that mixed functions, due to flexibility in performance, can manage the changes and in this case there is no need for social change in the area. [Figure 2]

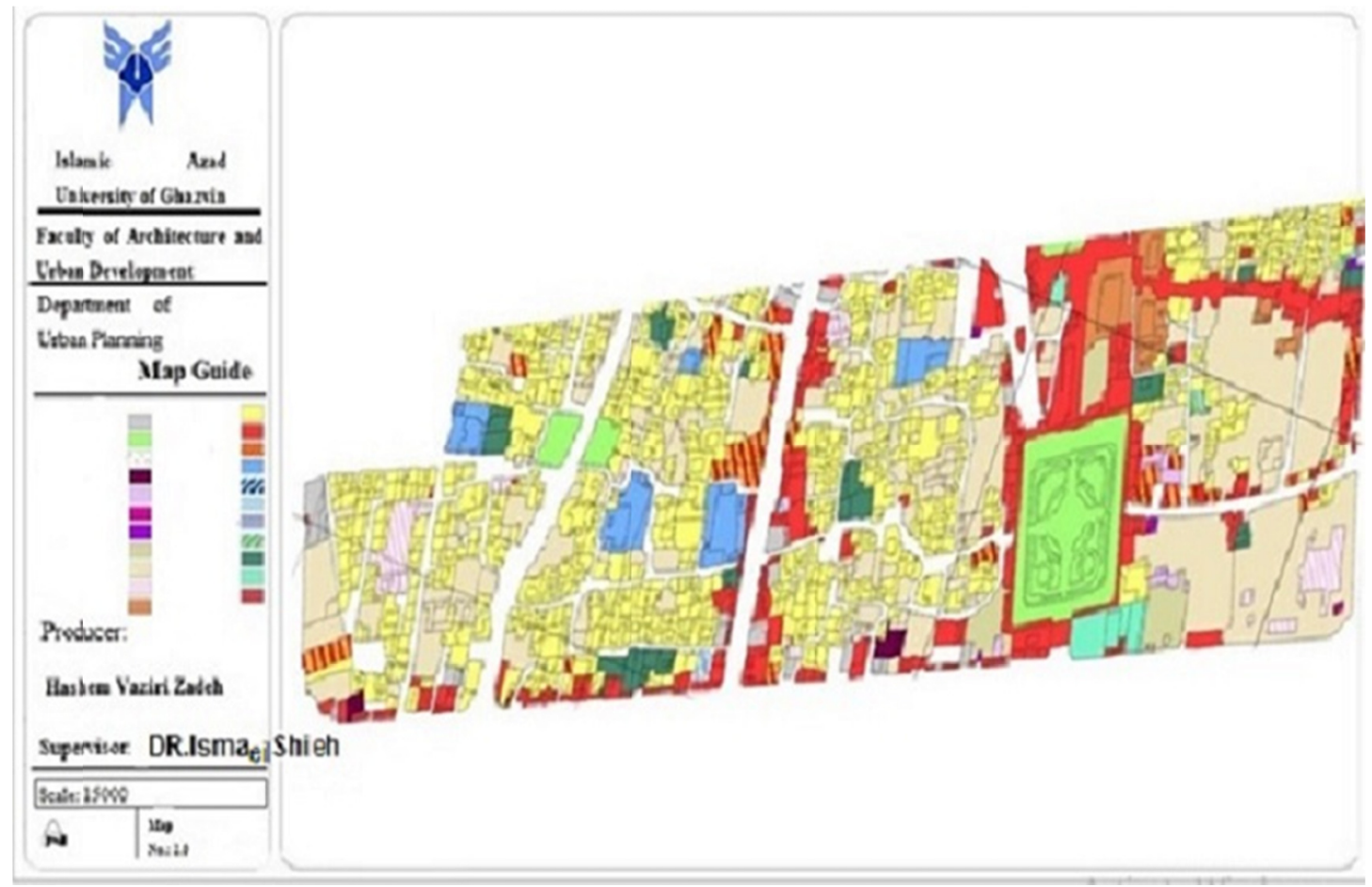

Figure 2. Functions of the status quo in Arg district

In this section, due to the high volume and large number of (swot) [Table 2 and 3], an example of them is presented. 
Table 2. measuring the economic capacities of Arg district through SWOT method

\begin{tabular}{|c|c|c|c|}
\hline Strengths (S) & Weak points $(\mathrm{W})$ & Opportunities (O) & Threats $(\mathrm{T})$ \\
\hline $\begin{array}{l}\text { - Attraction for } \\
\text { economic activities } \\
\text { Due to neighborhood with } \\
\text { Kerman market }\end{array}$ & $\begin{array}{l}\text { - Decrease of } \\
\text { residential functions } \\
\text { and increase of service } \\
\text { and commercial } \\
\text { functions }\end{array}$ & $\begin{array}{l}\text { - Possibility of attracting a } \\
\text { worthy share of division of } \\
\text { labor and economic activities } \\
\text { of Kerman with favorable } \\
\text { management }\end{array}$ & $\begin{array}{l}\text { - Lack of plans for } \\
\text { economic development } \\
\text { in order for } \\
\text { development }\end{array}$ \\
\hline $\begin{array}{l}\text { - Favorable situation of the } \\
\text { district in order to attract } \\
\text { leisure and touristic } \\
\text { activities }\end{array}$ & $\begin{array}{l}\text { - Low share of } \\
\text { professional } \\
\text { occupations }\end{array}$ & $\begin{array}{l}\text { - Excellence of the district in } \\
\text { terms of historical share }\end{array}$ & $\begin{array}{l}\text { - Lack of related } \\
\text { official's attention to } \\
\text { investment in creation } \\
\text { and development of the } \\
\text { area }\end{array}$ \\
\hline $\begin{array}{l}\text { - possibility of creation of } \\
\text { mixed functions in the } \\
\text { south part of Arg district } \\
\text { and its favorable } \\
\text { development }\end{array}$ & $\begin{array}{l}\text { - Tendency of the } \\
\text { private sector to invest } \\
\text { in land sector and } \\
\text { increase of business in } \\
\text { this sector }\end{array}$ & $\begin{array}{l}\text { - Closeness to the market of } \\
\text { major consumption }\end{array}$ & \\
\hline $\begin{array}{l}\text { Availability } \\
\text { sustainable income for } \\
\text { most of the residents }\end{array}$ & & $\begin{array}{l}\text { - Favorable accessibility and } \\
\text { neighborhood with Kerman } \\
\text { market }\end{array}$ & \\
\hline
\end{tabular}

Table 3. measuring the ecological capacities of Arg district through SWOT method

\begin{tabular}{|c|c|c|c|}
\hline Strengths (S) & Weak points (W) & Opportunities (O) & Threats (T) \\
\hline $\begin{array}{l}\text { Existence of } \\
\text { favorable green } \\
\text { space in Arg } \\
\text { square }\end{array}$ & $\begin{array}{l}\text { - Increase of destruction } \\
\text { and soil pollution }\end{array}$ & $\begin{array}{l}\text { - Possibility of receiving } \\
\text { investments and creation of } \\
\text { jobs by private and public } \\
\text { investors in order for } \\
\text { development of historical points } \\
\text { in the district and the } \\
\text { surrounding area }\end{array}$ & $\begin{array}{l}\text { - Intensification of water } \\
\text { resource constraints }\end{array}$ \\
\hline \multirow[t]{2}{*}{$\begin{array}{l}\text { - appropriation of } \\
\text { the environment } \\
\text { in Arg square }\end{array}$} & $\begin{array}{l}\text { - Osteoporosis of land } \\
\text { due to a sharp drop in the } \\
\text { level of groundwater that } \\
\text { makes the region more } \\
\text { vulnerable to earthquakes }\end{array}$ & $\begin{array}{l}\text { - Existence of touristic areas in } \\
\text { different points in the city and } \\
\text { possibility of attracting tourists }\end{array}$ & $\begin{array}{l}\text { - Lack of attention to local } \\
\text { advantages in allocating } \\
\text { construction funds in urban } \\
\text { level and mismanagement in } \\
\text { different sectors }\end{array}$ \\
\hline & $\begin{array}{l}\text { - Lack of robustness of } \\
\text { constructions against } \\
\text { earthquakes and not } \\
\text { observing construction } \\
\text { rules }\end{array}$ & & $\begin{array}{l}\text {-Drawdown of groundwater } \\
\text { in the province }\end{array}$ \\
\hline
\end{tabular}

Source: author 


\subsection{The Results of SWOT-Based Analysis}

SWOT analysis in general and in particular on the subject of research includes main points about Arg district area. The analysis suggests that the area has relative ability for quality improvement and development. By a glimpse it can be found that the position of Arg district in the city can be a solution to many problems in the area, especially for the elderly. The capacities available in the district in order for making it suitable for the elderly are much and this important issue can also become a model for the other areas. What is more important is location of the district in the historical and ancient structure of Kerman city and its being the destination of many residents and tourists. Making the available spaces suitable for the increasing presence of the elderly can provide dynamicity and sustainability of Arg district. The district space has special identity and image in the city and region scale and has more importance for the increasing presence of the residents and especially the elderly. Studies show that Iran's population is aging and this should not be considered as a crisis as it is not in developed countries. But the context for creating environment and city favorable for the elderly must be provided in order to prevent social problems. This important point will be provided when urban districts fitted to these needs (most of which are also common with the needs of other age groups) will be provided. Capabilities of Arg square and its immediate area including Kerman market must be designed and planned in accordance with these requirements in order to lead to dynamicity in space. [Table 4]

Table 4. requires criteria and sub-criteria to improve the local environment tailored to the needs of the elderly

\begin{tabular}{ll}
\hline Criteria & Sub-criteria \\
\hline Familiarity & 1. Keeping and strengthening familiar scenes \\
& 2. Keeping available furniture and minimum change in them \\
& 3. Use of local materials in the changes \\
4. Use of old furniture
\end{tabular}

Source: author 


\subsection{Offering the Solutions of Intervention in the Area and Planning}

In these solutions the possibility of trial and error is provided for the planner in order to get prepared for planning the best running actions and their operationalization, according to the considered criteria. These solutions have provided the possibility of hypothetical intervention and reveal its effects for the planner.

\section{The first solution:}

In this solution, planning is done with regard to the vacant lands so that the district will be prepared according to suitable and mixed functions for the elderly.

\section{The first solution:}

In this solution, according to local identity and Arg square, intervention and planning takes place.

The first solution:In this solution, planning is done in accordance with the vacant but at the same time valuable lands in the district (based on the position of the district in the city). Mixed functions in contrast with modernist regionalism have high value for attracting different age groups. One reason is that various and sometimes common needs of different age groups can be considered in these functions and help to promotion of spatial justice and also its dynamicity. The elderly's needs also have been paid much attention in these functions. In planning for building mixed buildings also local materials and architecture has been used and has caused promotion of attachment of the elderly and familiarity of the environment for them.

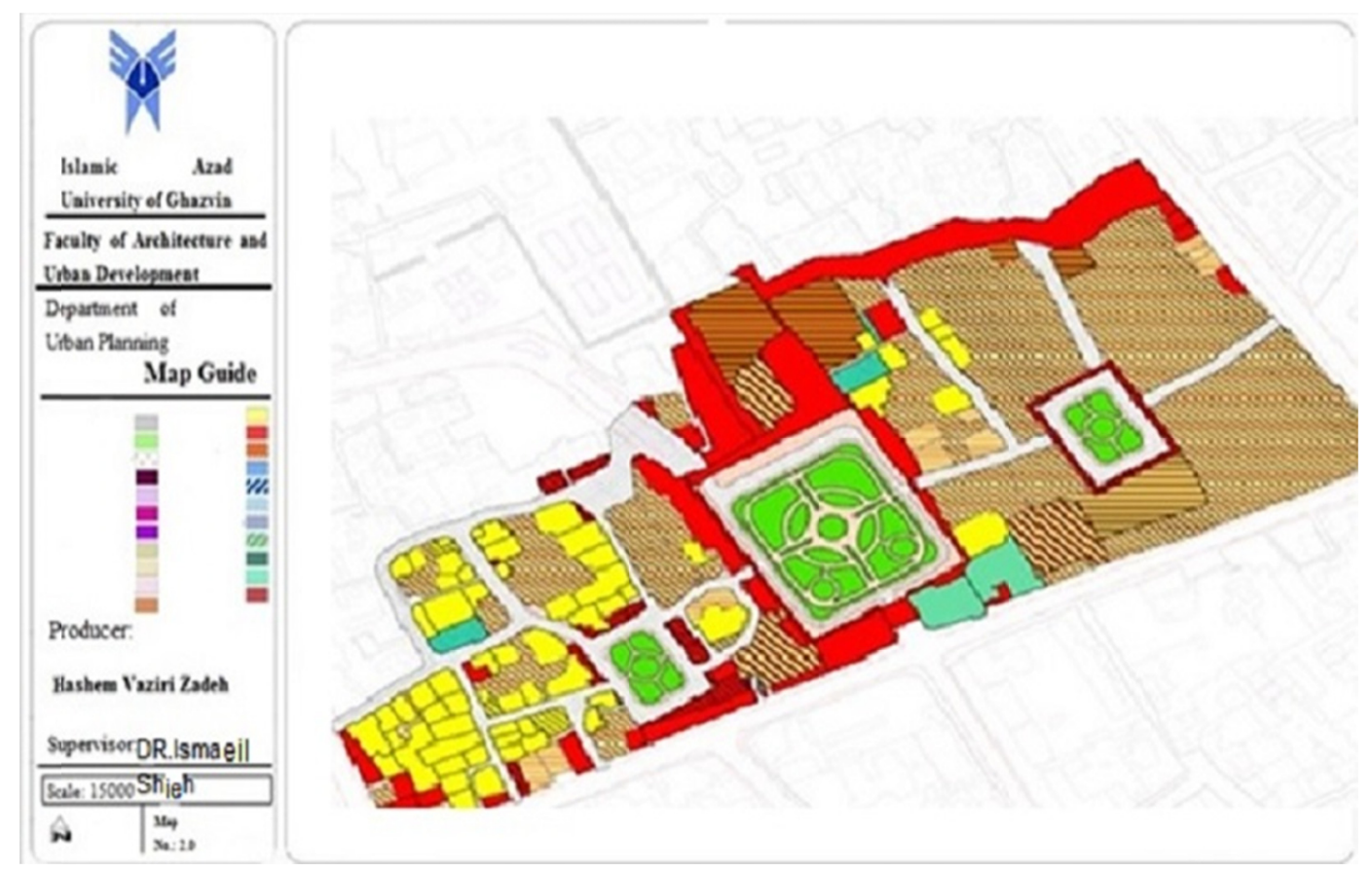

Figure 3. The first solution 


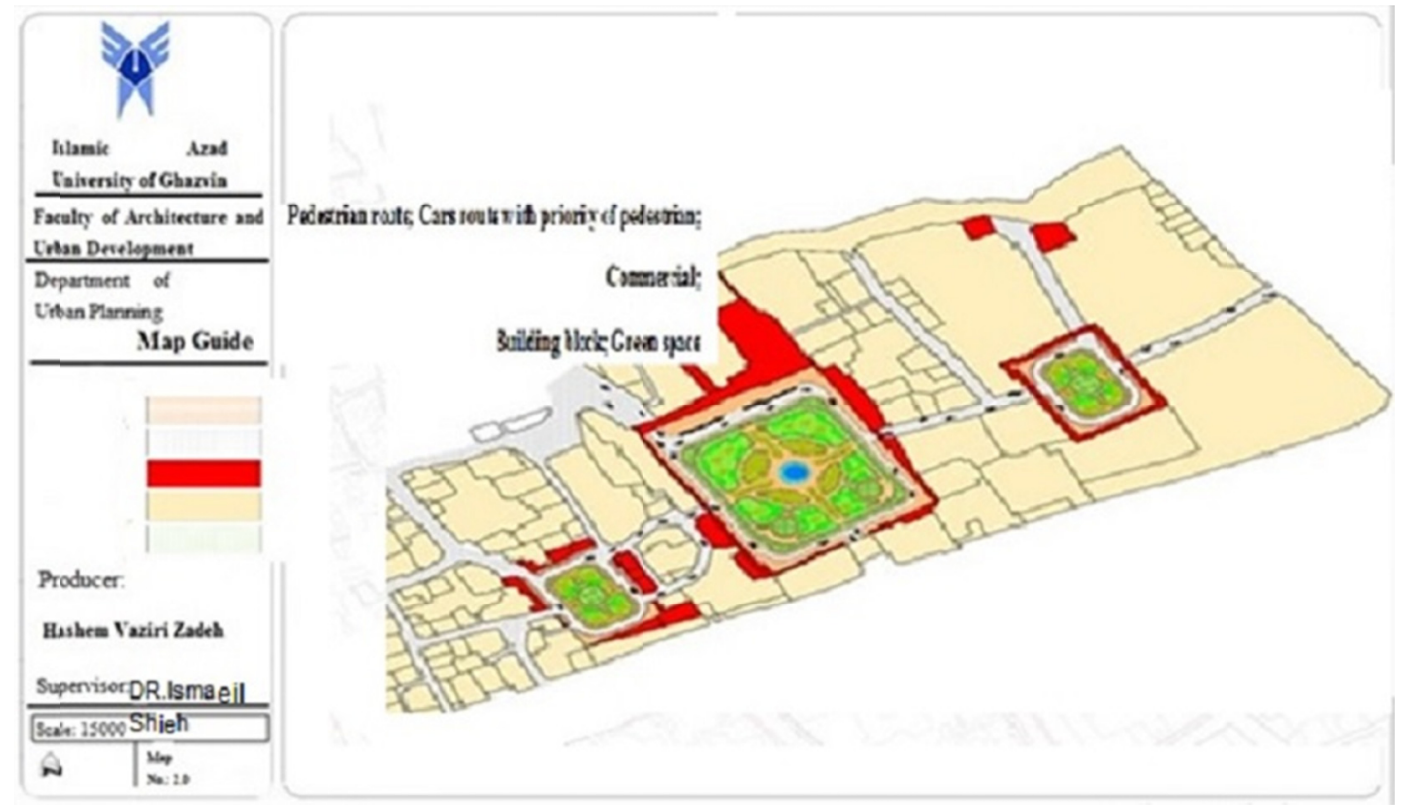

Figure 4. The second solution

The second solution: In [Figure 3 and 4] Planning has been done according to local identity and Arg square which acts as the entry of Kerman market. Around Arg square has been fitted according to the needs of the elderly with comfortable furniture fitted for the elderly. Routs have been fitted for the elderly's accessibility; and signs existing in the district have been strengthened and light and color has been used in order for better readability of signs and symptoms and environment familiarity for the elderly. Also light and color has been used for beautification of sidewalks environment for overnight presence. In this solution, improvement of local identity has become possible by strengthening Arg square and continuity of the route for the elderly.

\subsection{Evaluation of the solutions utilizing AHP technique}

One of the most efficient techniques is AHP (Analytical hierarchy process) which was firstly introduced by Thomas L. Saaty in 1970s. This technique is based on pair comparisons and gives the possibility of considering different scenarios. Analytical hierarchy process (AHP) is one of the most comprehensive designed systems in order for decision making with multi-criteria, because this technique provides the possibility of formula making of the problem hierarchically and also has the possibility of considering different quantitative and qualitative criteria in the problem. This process involves different options in decision-making and has the possibility of sensitivity analysis on criteria and sub-criteria. In addition to this, it is based on pair comparison which facilitates judgments and calculations; also it shows the amount of compatibility and incompatibility of the decision which is among the privileged advantages of this technique in multi-criteria decision making. Evaluation of solutions is done according to the planning criteria mentioned in the research. [Table 5] 
Table 5. The criteria and their scores compared to the solutions

\begin{tabular}{|c|c|}
\hline Criteria & Score of criteria compared to the solutions \\
\hline \multicolumn{2}{|l|}{ Familiarity } \\
\hline & $\$ 1.654$ \\
\hline & $\$ 2.346$ \\
\hline \multicolumn{2}{|l|}{ Readability } \\
\hline & $\$ 1.345$ \\
\hline & $\$ 2.655$ \\
\hline \multicolumn{2}{|l|}{ Being } \\
\hline \multirow[t]{2}{*}{ recognizable } & $\$ 1.440$ \\
\hline & $\$ 2.560$ \\
\hline \multirow[t]{3}{*}{ Accessibility } & \\
\hline & $\$ 1.451$ \\
\hline & $\$ 2.549$ \\
\hline \multirow[t]{3}{*}{ Convenience } & \\
\hline & $\$ 1.537$ \\
\hline & $\$ 2.463$ \\
\hline \multirow[t]{2}{*}{ Security } & $\$ 1.400$ \\
\hline & $\$ 2.600$ \\
\hline \multirow[t]{3}{*}{ Beautification } & \\
\hline & $\$ 1.550$ \\
\hline & $\$ 2.450$ \\
\hline
\end{tabular}

Source: author

As is clear from the assessments, the second solution has a higher score and is introduced as the top model

\subsection{Recommendations}

The elderly are considered part of vulnerable citizens that urban spaces should be made appropriate specifically for them. They need interaction with urban social space and contact with nature, walking and exercise. But physical weaknesses and in some cases isolation makes their use pattern of urban areas different. Correct understanding of aging phenomenon needs wide studies. As the elderly are considered among the low-ability people of the society, they need special care and attention so that as much as possible, their health will not be negatively affected by environmental (urban and local) factors. Also by creating a desirable and joyful environment for the elderly, the context for their health will be provided more than ever. In planning for creating favorable district for the elderly in Kerman Arg district, some principles were used in order to provide a favorable environment. Several strategies also are pointed out in order for implementation of the mentioned principles:

- Expansion of pedestrian routs throughout Arg district and flooring in accordance with local materials

- Organizing furniture and local landmarks in the area and use of local architecture in creation of changes 
- Placement of convenient and suitable furniture at low distances, and in places next to Arg square which are considered behavioral sites of the elderly

- Organizing behavioral sites of the elderly in order for their more presence in Arg district environment

- Securing the routs and streets of the district especially the intersections, for the elderly

- Spreading the culture of respect for the rights of the elderly in public spaces

- Calling for participation of different groups, particularly the elderly, in order to pay attention to their needs in the process of preparing plans

- Using natural and local elements in beautification and increasing subtlety of the environment of Arg district for the elderly

- Providing security for pedestrians at intersections and on main streets sidewalk

- Making cultural programs on radio and television for awareness of the community about problems and issues of the elderly.

\section{Discussion}

Efforts done for making the urban environment appropriate for the elderly especially in developing countries are very few and rare while formulation of principles and criteria of planning and designing also are at their primary levels. In the past, some actions have been done in order for providing comfort and relaxation of the elderly regarding easy access to residential environment; but regarding district environment (that the elderly are much dependent on that) no action has been done and different social, economic, physical and environmental dimensions in order for presence of the elderly have not been analyzed and modeled. Meanwhile, the context for the considered actions and formulation of issues within the framework of urban rules and plans has also been faced with basic gap in this regard and the approaches regarding the appropriation of the local urban environment for the elderly has been mostly based on personal manners. For this purpose and with regard to aging of the world's population and in order for making the urban environment fitted for the elderly, comprehensive studies from various socio-economic and physical and environmental aspects must be done and strategies for modeling for other points be extracted. Certainly calling to participation of different groups and especially the elderly in this regard can have very positive effects. It seems that during the planning process in providing urban plans, the legal and executive status for the elderly has not been taken into account; and according to the procedure of providing plans, special attention must be paid to the structure of the population of the area and, tailored to the elderly population of different areas of the city, the districts which have more aging population, planning must be done in order to appropriate the environment for them and it must be designed and implemented. On the other hand, appropriation of the urban environment for the elderly leads to improvement of local attachment of the residents. Presence of people in different age groups in local environment improves security and calmness of the district and because of presence of the elderly, social and behavioral abnormalities will decrease. Kerman Arg district is valuable due to its historical potentials and identity signs for the residents of the district and meta-district and this value is doubled because of the residents' attachment, because over time they have been in contact with this environment more. Sudden changes which are incompatible with the district will hurt this link and provides the context for their damage. Planning should be in the direction that comprehensive studies will be done in order for making changes. Old age is an important period of human life that is along with great physical, psychological and social changes. These changes cause change in behavioral patterns especially in the area of individual health care that is called "lifestyle". Healthy lifestyle is a way that leads to providing and maintaining level of health, welfare and quality of life of the individual. From the perspective of the World Health Organization, the dimensions of a healthy lifestyle for the elderly includes observing appropriate nutrition principles, observing personal hygiene, enough sleep and rest and physical activity during a day, not using tobacco, regular periodic checkups, having mental health and participation of the old person in social activities along with family. Old age pathology is a comprehensive approach to identify and recognize lack of local services that do preventive actions and therapeutic interventions and evaluates its effects. For an effective service to the elderly community, we should benefit from the experiences of other communities and countries of the world, and we should have specified, calculated and applicable policies and planning and programs. On the other hand, some of the needs of the elderly of any community are just particular to that community and using the experiences of other communities is not efficient alone. Protecting the elderly also should not be done only with the aim of increasing their life expectancy. Today, dynamic old age is the main objective; that is, with increase of the elderly population, the quality of their lives should also be addressed. The issue of quality of life in different classes, particularly in those who have special physical, mental and emotional 
conditions, and are faced with complexities due to the special condition, is very important. Old age is a sensitive period of human life that attention to the problems and needs of this phase is a social necessity. Given the particular needs of this period, attention to behaviors which improve health and quality of life in the elderly is also a very important issue that is largely neglected.

\section{References}

Eftekhari, E. (2013). Authors of the paper of offering a new approach in urban design: Designing old-centered and ergonomic city with an approach to (urban) environmental rehabilitation; National Conference on Human-oriented architecture and urban planning, Tehran.

Kakayee, F. (2016). Authors of the paper of recovery of signs in urban spaces; The First Scientific-Research Conference of civil architecture and environmental sustainability, Tehran, Institute of Architecture and Urban Planning of Ivan Shams.

Khansari, G., \& Negahi, M. (2006). The notion of district and suggesting a solution. Saffe journal, (43).

Poorjafar, M., \& Taghvayee, A. (1999). Attention to the needs of the elderly in urban design; The First International Conference on the Elderly in Iran; Tehra.

Sarrafi, M. (2014). Examining the optimal environment quality (urban space) in relation to the elderly; The second National Conference on architecture, construction, urban development and environmental sustainability, Tehran.

Teymoori, F., Ameri Siahooee, H., \& Ahmadi Sarkhooni, F. (2015). Examining the role of architectural design in improvement of social interactions of the elderly in urban spaces; International Conference of civil architecture and urban development at the beginning of the third millennium.

Zabetian, A. (2009). Indicators of appropriation of aged-friendly urban spaces by using a participatory approach; Housing Foundation, Journal of Housing and Rural Environment, (711).

\section{Copyrights}

Copyright for this article is retained by the author(s), with first publication rights granted to the journal.

This is an open-access article distributed under the terms and conditions of the Creative Commons Attribution license (http://creativecommons.org/licenses/by/4.0/). 